\title{
BIOCHEMICAL AND PATHOLOGICAL EFFECTS OF PALM, MUSTARD AND SOYBEAN OILS IN RATS
}

\author{
M. S. Hoque ${ }^{1}$, M. E. Kabir ${ }^{1}$, M. M. Hasan ${ }^{2}$, M. T. Rahman ${ }^{3}$, M. Rashid ${ }^{1}$, T. Ruba ${ }^{1}$, \\ M. H. Rahman ${ }^{1}$, A. B. M. J. Uddin ${ }^{1}$ and M. M. Hossain ${ }^{1 *}$ \\ ${ }^{1}$ Department of Pathology, ${ }^{2}$ Department of Medicine, Faculty of Veterinary Science, Bangladesh Agricultural \\ University, Mymensingh-2202, Bangladesh; ${ }^{3}$ Department of Para-clinical courses, Faculty of Veterinary \& \\ Animal Sciences, Gono Bishwabidyalay (Gono University), Dhaka, Bangladesh.
}

\begin{abstract}
The investigation was conducted to determine the effects of different edible oils in experimental animals. A total of 36 male Long Evans rats of one month age were randomly divided into four equal groups. Rats of Group A were kept as control by feeding rat pellet. Rats of Group B, C and D were fed rat pellet by mixing of palm, mustard and soybean oils respectively, at the dose of $15 \%$ in feed for 6 months. The methods included determination of weight gains, lipid profiles and histopathological lesions in different organs: aorta, liver, heart and kidneys at 0 day, 3 months and 6 months interval. All experimental rats exhibited progressive weight gain during the research period and soybean oil treated group showed the highest significant $(\mathrm{P}<0.01)$ body weight gain $(153 \%)$ but mustard oil resulted significant $(\mathrm{P}<0.05)$ increased liver weight $(4.557 \mathrm{~g})$ after 6 months. Soybean oil showed significant $(\mathrm{P}<0.01)$ increased total cholesterol $(204.25 \mathrm{mg} / \mathrm{dl})$, HDL (53.15 $\mathrm{mg} / \mathrm{dl})$ and LDL $(113.06 \mathrm{mg} / \mathrm{dl})$ than other groups. Triglyceride levels of all oil treated groups were significantly $(\mathrm{P}<0.05)$ lower than control group. Histopathology revealed that palm oil fed group had fatty liver, narrowed blood vessel and thickened aorta of heart. Soybean oil fed group also showed narrowed blood vessels but mustard oil fed group showed no noticeable change in the mentioned vital organs. After the investigation, mustard oil proved comparatively better than palm and soybean oil.
\end{abstract}

Keywords: Edible oil, body weight, lipid profile, histopathology, rats

\section{INTRODUCTION}

At present, cardiovascular diseases are of great concern for human being and companion animals due to changing of socioeconomic condition as well as eating and drinking behavior. Among the risk factors (excess fat/lipid intake, age, lack of exercise, smoking, drinking alcohol, diabetes, etc.), intake of high lipid/fat containing food is of prime importance for cardiovascular diseases. Lipids play an important role to supply energy for meeting the calorie requirements and act as storage and transport forms of metabolic fuel. Each gram of fat or oil supplies $9 \mathrm{kcal}$ energy which is about double than those of energy provided by proteins or carbohydrates. Current recommendations are to limit dietary fat and cholesterol consumption to $30 \%$ or less of total calories or $300 \mathrm{mg}$ or less per day (Baron and Browner, 1998) and saturated fat should not be made more than $15 \%$ of the total fat intake. High fats and oils intake with diet cause diseases like atherosclerosis, ischemic heart disease, chronic nephritis, obesity, hypertension, diabetes etc. which are reported in both human and animals (Kagawa et al., 1998; Austin et al., 2000; Jakobsen et al., 2009; Soler and Ruiz, 2010; Xenoulis and Steiner, 2010). The presence of cholesterol, saturated fatty acids (Wood et al., 1966) and trans fatty acids in fats and oils increase the risk of coronary heart diseases by increasing the blood cholesterol (Lichtenstein, 1988).

In Bangladesh, epidemiological study on heart diseases in man is related with dyslipemia or obesity were reported, (Zaman et al., 2007; Sayeed et al., 2010; Islam et al., 2002; Islam and Majumder, 2012) but information on heart diseases of companion animals (i.e., dog, cat, etc.) is not yet to be found. The data of high quantity and prolong use of palm (saturated fatty acids), mustard oil (monounsaturated fatty acids) and soybean oil (polyunsaturated fatty acids) in humans and laboratory animals are very scanty in Bangladesh (Rahman, 2009). As it is difficult to carry out research on human and companion animals (dogs and cats), the laboratory animals (rats) were chosen as the experimental model for this study. Therefore, the present experiment was designed to study the effect of selected edible oils (palm, mustard and soybean oils) in body and organs weight gain, changing on lipid profiles and examine the pathological changes of vital organs in rat at different time intervals.

*Corresponding e-mail address: mmhossain04@yahoo.com.au 
Hoque and others

\section{MATERIALS AND METHODS}

The experiment was conducted in the Department of Pathology, Bangladesh Agricultural University (BAU), Mymensingh during the time of February to August 2016. The following procedures were adopted for conducting the experiment.

\section{Statement of Animal Ethics}

In this study no animals were suffered from hazards for the experiment and had followed ethical guide for care and use of laboratory animals. The procedure of the experiment was approved by the Animal Welfare and Ethical Committee on Laboratory Animal Use of the Faculty of Veterinary Science, Bangladesh Agricultural University.

\section{Experimental rats and diets}

A total number of 36 one month aged Long Evans rats were purchased from International Center for Diarrhoeal Disease Research, Bangladesh (ICDDR'B). The rats were randomly divided into four equal groups (A, B, C \& D. 9 rats in each group). All groups of rats were housed in compartmented metallic cages. The rat cages were kept in well ventilated room with natural day and light. Temperature $\left(28 \pm 2^{\circ} \mathrm{C}\right)$ and humidity $(70-80$ $\%$ ) of laboratory were always kept under care. Initially, rats were fed with ordinary rat pellet for 7 days to adjust into new environment. The feeds were purchased from ICDDR'B, Dhaka and the test oils (soybean, palm, and mustard oil) were purchased from local market of Mymensingh, Bangladesh. Among four groups, A group was kept as control by feeding normal rat pellet and other three groups (B, C \& D) were fed rat pellet by mixing palm, mustard and soybean oils respectively, at the dose of $15 \%$ (Gaiva et al., 2003). The experiment was continued for 6 months. Body weight, organ weight and histopathology samples (heart, liver, kidney and aorta) of each rat from all groups were taken at 0 day of experiment, 3 months and 6 months. Blood was collected for lipid profile analysis at 0 day of experiment, 3 months and 6 months. Proper hygienic and sanitary measures were also adopted during the experimental period and had followed ethical guide for care and use of laboratory animals.

\section{Weight gain}

Initial body and organ weight of each rat was measured with the help of an electric balance. Body and organ weight was taken at 0 day, 3 months and 6 months age.

Weight gains $(\mathrm{g})=$ Mean final weight $(\mathrm{g})-$ Mean initial weight $(\mathrm{g})$

Percent weight gain $(\mathrm{g})=[$ Mean final weight $(\mathrm{g})$-Mean initial weight $(\mathrm{g})] /($ Mean initial weight $) \times 100$

\section{Biochemical studies}

\section{Collection of blood and serum preparation}

For biochemical study, the experimental rats were starved overnight at 0 day, 3 months and 6 months of age. Anesthesia was done with chloroform using self-made gas chamber and 2-3 $\mathrm{ml}$ of blood was collected in the sterile glass test tubes directly from heart after opening. The blood containing tubes were placed in slanting position at room temperature for 6 hours. The tubes were then incubated overnight in the refrigerator $\left(4^{\circ} \mathrm{C}\right)$. The serum samples were separated and centrifuged to get rid of unwanted blood cells where necessary. Serum samples were stored for biochemical analysis of lipid profiles.

\section{Analysis of Lipid Profiles}

The biochemical parameters of lipid profile like total cholesterol (TC), triglycerides (TG), serum cholesterol HDL (high density lipoprotein) and serum cholesterol LDL (low density lipoprotein) were determined in the central lab of BAU using different kits (Crescent diagnostics, cat no. Cs. 603 and Atlas medical) and where LDL level was measured by the Friedwald equation (Friedwald et al., 1972) as follow: LDL cholesterol $(\mathrm{mg} / \mathrm{dl})=$ Total cholesterol - HDL cholesterol $-($ Triglyceride $/ 5)$

\section{Histopathology}

The liver, kidney, heart and aorta from each group of rats were collected in $10 \%$ neutral buffered formalin for 15 days. The well fixed tissues were processed, sectioned and stained as per standard procedure (Luna, 1968) in Department of Pathology, Bangladesh Agricultural University, Mymensingh.

\section{Statistical analysis}

The body weight gains of the experimental rats of different groups were computed by performing analysis of covariance in randomized complete block design (Gomez and Gomez, 1984). The mean organ weights of the different groups were compared with the control by Dunnett's test procedure (Steel and Torrie, 1980). 


\section{RESULTS AND DISCUSSION}

This study was conducted on Long Evans rats to observe the effects of supplementing diets with marked edible oils soybean, palm and mustard oil on growth, lipid profile and histopathological changes in some selected organs for a period of 6 months. Body and organ weights were recorded at 0 day, 3 months and 6 months of age. Lipid profile and histopathological investigation were carried out at same age respectively after sacrificing the rats.

\section{Growth performance}

Body weight: The body weight gain percentages in different groups are shown in Table 1. All the edible oil treated rat groups had significantly $(\mathrm{P}<0.01)$ increased body weight gain than control group. After 3 months, control group weight gain percentage was 51, whereas in palm, mustard and soybean weight gain percentages were 102, 104.44 and 103.78 respectively. The highest weight gain occurred in soybean oil fed treated rat group $(153 \%)$ after 6 months of age, less than in palm (131.63\%), mustard (109\%) and control group (51\%). Besides, as shown in Table 2, there was significant $(\mathrm{P}<0.05)$ difference in body weight gain among the edible oil treatment groups. The observed findings supported by the experimental studies where edible oil especially soybean was effective in increasing body weight gain (Rashid et al., 1998; Barek, 2002; Gaiva et al., 2003; Rahman et al., 2012) in different animals.

Table 1. Comparison of body weight gain percentage at 3 months and 6 months of age in different treatment groups by Dunnett's test procedure

\begin{tabular}{c|c|c|c}
\hline Serial & $\begin{array}{c}\text { Treatment } \\
\text { Group }\end{array}$ & $\begin{array}{c}\text { \% body weight } \\
\text { gain at 3 months }\end{array}$ & $\begin{array}{c}\text { \% body weight } \\
\text { gain at 6 months }\end{array}$ \\
\hline 1 & Control & 51 & 51 \\
2 & Palm & $102^{* *}$ & $131.63^{* *}$ \\
3 & Mustard & $104.44^{* *}$ & $109^{* * *}$ \\
4 & Soybean & $103.78^{* *}$ & $153^{* *}$ \\
\hline
\end{tabular}

${ }^{* *}$ indicates that values having double asterisk within the same column differ significantly $(\mathrm{P}<0.01)$.

Table 2. Analysis of variance (ANOVA) for body weight gains of the experimental rats

\begin{tabular}{c|c|c|c|c}
\hline Source of variance & Sum of Squares & Degree of freedom & Mean Square & Sig. \\
\hline Between Groups at 3 month & 1068.917 & 3 & 356.306 & .012 \\
Between Groups at 6 month & 9843.667 & 3 & 3281.222 & .001 \\
\hline
\end{tabular}

From this table, it could be interpreted that there is existence of significant $(\mathrm{P}<0.01)$ difference among the treatment groups.

Organ weight: The proportional organ weight percentage is shown in relation with the body weight of the rats of different treatment groups at day 0,3 months and 6 months in Table 3. The study findings revealed that edible oil treatment had impact on organ weight gain in rats. From Dunnett's test, heart weight showed no statistically significant difference in edible oil treated groups compared to control group in both at 3 months and 6 months of age. Mustard oil had significant $(\mathrm{P}<0.05)$ impact on increasing liver $(4.557 \mathrm{~g})$ weight where palm oil significantly $(\mathrm{P}<0.05)$ reduced the liver weight $(2.846 \mathrm{~g})$, than control group $(3.497 \mathrm{~g})$ after at the age of 6 months. In kidney, palm and mustard oil significantly $(\mathrm{P}<0.05)$ reduced the kidney weight from their initial value, but soybean oil treated group significantly $(\mathrm{P}<0.05)$ increased the weight at 3 months of age and found significant $(\mathrm{P}<0.05)$ reduced weight at 6 months of age. Saha et al. (2005) reported that higher liver weight gain in mustard oil fed group than palm and soybean, where this study had similar findings compared with control and other groups. Palm oil caused reduction of kidney weight in rat, this result also corroborated by Jaarin et al. (2015). 
Hoque and others

Table 3. Comparison of the organ weight proportional percentage in relation to body weight in 0 day, 3 months and 6 months of age of different treatment group by Dunnett's test procedure

\begin{tabular}{|c|c|c|c|c|c|}
\hline \multirow{2}{*}{ Organ weight gain } & \multirow{2}{*}{ Time } & \multicolumn{4}{|c|}{ Experimental Group } \\
\hline & & Control & Palm & Mustard & Soybean \\
\hline \multirow{3}{*}{ Heart (mg) } & 0 day & 0.380 & 0.379 & 0.377 & 0.373 \\
\hline & 3 months & 0.330 & 0.359 & 0.338 & 0.340 \\
\hline & 6 months & 0.311 & 0.325 & 0.331 & 0.312 \\
\hline \multirow{3}{*}{ Liver $(\mathrm{g})$} & 0 day & 4.080 & 4.110 & 4.090 & 4.130 \\
\hline & 3 months & 3.711 & 3.310 & $4.660^{*}$ & 3.730 \\
\hline & 6 months & 3.497 & $2.846^{*}$ & $4.557^{*}$ & 3.424 \\
\hline \multirow{3}{*}{ Kidney- L (mg) } & 0 day & 0.458 & 0.445 & 0.450 & 0.461 \\
\hline & 3 months & 0.363 & $0.313^{*}$ & 0.408 & $0.465^{*}$ \\
\hline & 6 months & 0.342 & 0.332 & $0.398^{*}$ & $0.427^{*}$ \\
\hline \multirow{3}{*}{ Kidney- R (mg) } & 0 day & 0.472 & 0.462 & 0.471 & 0.467 \\
\hline & 3 months & 0.355 & $0.331^{*}$ & $0.331^{*}$ & $0.471^{*}$ \\
\hline & 6 months & 0.334 & 0.341 & $0.416^{*}$ & $0.433^{*}$ \\
\hline
\end{tabular}

* indicates that values having asterisk within the same column differ significantly $(\mathrm{P}<0.05)$.

\section{Lipid Profile Analysis}

Table 4 reveals the comparative analysis of lipid constitutes of experimental edible oil treated rat groups and control group in different time periods. The changes of lipid profiles value were significant in edible oil treated rat group than control group. At 0 day, the findings were similar in all experimental groups. The serum cholesterol level of three treatments were significantly $(\mathrm{P}<0.05)$ lower than the control group $(189.1 \pm 4.19965)$ after 3 months of age, where soybean oil treated group showed the lowest value $(165.5733 \pm 5.89714)$ and this findings agree with the results of other experimental studies (Islam et al. 2009, Erukainure et al. 2016). In contrast, palm and soybean oil caused significant $(\mathrm{P}<0.05)$ increase of cholesterol level and mustard oil caused significant $(\mathrm{P}<0.01)$ decrease of cholesterol level than control group after 6 months of age (Table-04). In comparing with the 3 months and 6 months cholesterol level values of edible oil treatment group and control group, the study revealed that a sharp contrast in between the results of both treatment groups and control group but it agrees with the findings of Fernandez et al. (1996) and Choi et al. (1993). At 3 months, soybean oil caused significant $(\mathrm{P}<0.05)$ decrease of TG $(150.96 \pm 3.66)$ than control group $(179.75 \pm 3.92)$ whereas palm and mustard oil caused significant $(\mathrm{P}<0.01)$ increase of TG $(185.31 \pm 4.92 \& 193.23 \pm 2.97$ respectively $)$. But at 6 months, all the oil groups caused significant $(\mathrm{P}<0.01)$ decrease of TG. The study results of Islam et al. (2009) and Erukainure et al. (2016) having similar results of this experiment after 6 months.

The result of the Dunnett's test indicates that palm and soybean oil caused significant $(\mathrm{P}<0.05)$ increase HDL level at 3 and 6 months but mustard oil showed no significant changes than control group (Table-04). Islam (2002) also reported that the value of HDL increased in case of giving $2 \%$ soybean supplement with feed in broiler. In this study, LDL level decreased significantly $(\mathrm{P}<0.05)$ in all edible oil treated groups after 3 months whereas soybean oil $(113.06 \pm 9.32)$ and palm oil $(99.04 \pm 9.09)$ caused significant $(\mathrm{P}<0.05)$ increased level of LDL after at 6 months (Table 4). LDL value of different treatment rat groups agreed with the result of Islam $e t$ al. (2002) after 3 months but it was different at 6 months of age. 
Table 4. Comparisons of lipid profile (TC, TG, HDL and LDL) levels at 0 day, 3 months and 6 months of age in different treatment groups by Dunnett's test procedure

\begin{tabular}{ccccccc}
\hline \multirow{2}{*}{ Lipid Profile } & \multirow{2}{*}{ Time } & \multicolumn{4}{c}{ Experimental Group } \\
\cline { 3 - 6 } & & Control & Palm & Mustard & Soybean \\
\hline \multirow{2}{*}{ TC mg/dl } & 0 day & $113.99 \pm 2.18$ & $114.2 \pm 2.11$ & $112.12 \pm 1.89$ & $114 \pm 2.02$ \\
& 3 months & $189.1 \pm 4.19$ & $187.15 \pm 1.86^{*}$ & $171.67 \pm 1.99^{* *}$ & $165.57 \pm 5.89^{* *}$ \\
& 6 months & $182.23 \pm 1.06$ & $186.00 \pm 4.71^{*}$ & $175.18 \pm 4.67^{* *}$ & $204.25 \pm 3.43^{*}$ \\
\hline \multirow{2}{*}{ TG mg/dl } & 0 day & $76.13 \pm 2.38$ & $75.15 \pm 1.85$ & $74.17 \pm 2.12$ & $78.24 \pm 2.11$ \\
& 3 months & $179.75 \pm 3.92$ & $185.31 \pm 4.92^{*}$ & $193.23 \pm 2.97^{*}$ & $150.96 \pm 3.66^{* *}$ \\
& 6 months & $196.17 \pm 7.49$ & $186.36 \pm 5.74^{*}$ & $182.76 \pm 8.04^{*}$ & $176.64 \pm 7.68^{*}$ \\
\hline HDL mg/dl & 0 day & $42.14 \pm 1.05$ & $41.13 \pm 1.25$ & $40.12 \pm 2.10$ & $41.23 \pm 2.12$ \\
& 3 months & $40.01 \pm 5.58$ & $47.12 \pm 6.87^{*}$ & $38.87 \pm .71$ & $46.85 \pm 4.84^{*}$ \\
& 6 months & $41.85 \pm 2.78$ & $46.68 \pm 4.52^{*}$ & $39.54 \pm 2.32$ & $53.15 \pm 27^{* *}$ \\
\hline \multirow{2}{*}{ LDL mg/dl } & 0 day & $99.64 \pm 1.82$ & $98.50 \pm 1.45$ & $99.50 \pm 1.25$ & $98.32 \pm 1.02$ \\
& 3 months & $105.36 \pm 3.94$ & $96.20 \pm 6.40^{*}$ & $97.47 \pm 5.54^{*}$ & $86.53 \pm 7.53^{* *}$ \\
& 6 months & $94.36 \pm 12.95$ & $99.04 \pm 9.09^{*}$ & $93.07 \pm 9.62$ & $113.06 \pm 9.32^{* *}$ \\
\hline
\end{tabular}

Values having asterisks within the same column differ significantly $\left({ }^{* *}\right.$ indicates $\mathrm{P}<0.01,{ }^{*}$ indicates $\left.\mathrm{P}<0.05\right)$.

\section{Histopathological Examination}

The histopathological studies of heart, liver, aorta and kidney tissues were performed to investigate the effects of different oil-supplementation in rats of 3 and 6 months of age. Among all the edible oils, the palm oil treated group showed only significant lesions on heart blood vessels, liver and aorta. In heart, the blood vessels wall had become thickened in palm and soybean oil treated rat groups (Figures $1 \& 2$ ). The aorta wall had become thickened in the palm oil treated rat group which indicates the arterioscelorisis (Figure 3). Further, section of liver of control group, soybean oil and mustard oil treated rat groups showed normal histology without showing any detectable lesions but severe fatty changes in liver were found in palm oil group (Figure 4). Few studies reported that palm oil was responsible for degenerative changes in hepatocytes, congestion of central vein and fatty changes in liver (Jaarin et al., 2015; Saha et al., 2005), and these reports upheld the result of this experiment. In addition, the present experiment showed only mild inflammation in kidney of mustard oil fed rat group where other oil fed groups showed normal histoarchitecture. So histopathologically palm oil proved as the worst and mustard oil proved as the best one among these three groups.

From the present experiment it could be concluded that edible oils have effect on growth performance and lipid profiles in rat. After the investigation, on the basis of TC, HDL, LDL level and histopathology, it is clear that mustard oil had less harmful effect on body than the other oils although it was observed that the results of 3 months age were quite different than the result of 6 months of age. There may have age relation or something else that caused this variation. However, it is a preliminary work and in future this would require further study for better explanation in this regard. 


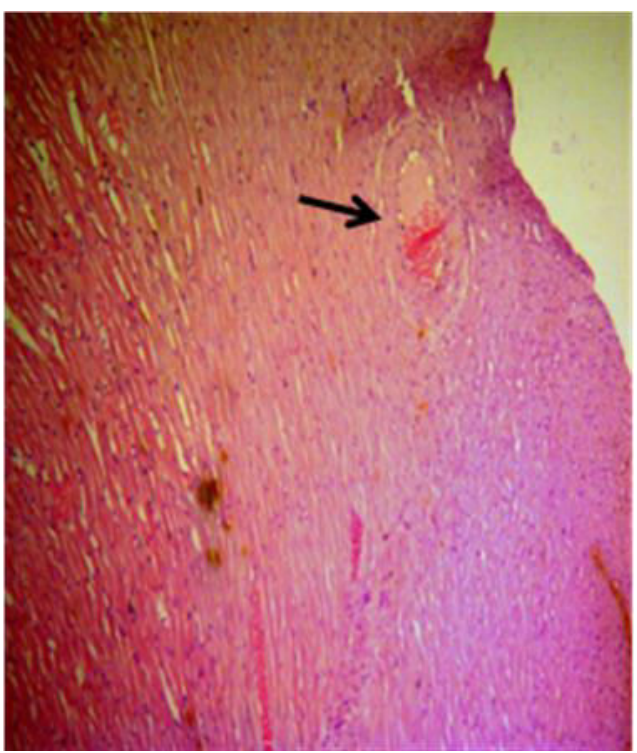

Figure 1. Section of heart: Palm oil treated rats group. Arrow mark Shows narrowing of blood vessel. (H \& E staining, 10X)

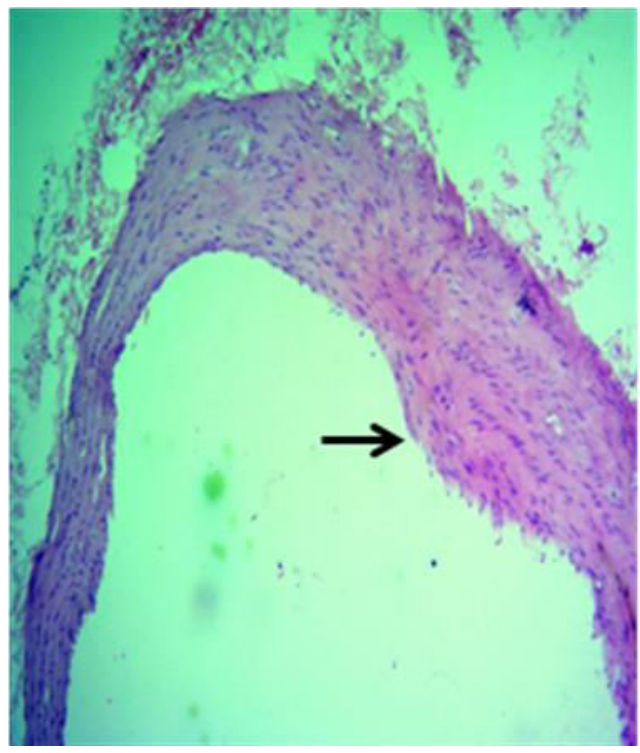

Figure 3. Section of aorta: Palm oil treated rats group. Arrow shows thickening of aorta. (H \& E staining, 10X)

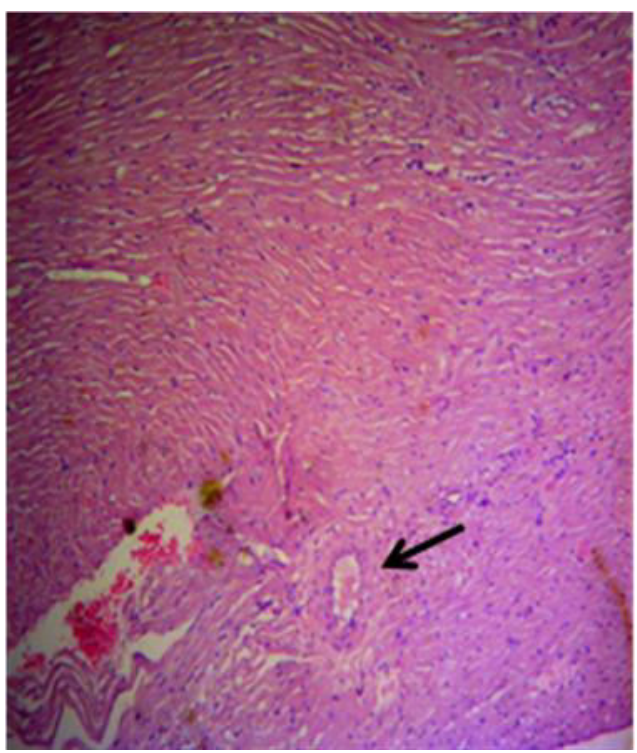

Figure 2. Section of heart: Soybean oil treated rats group. Arrow mark shows narrowing of blood vessel. (H \& E staining, 10X)

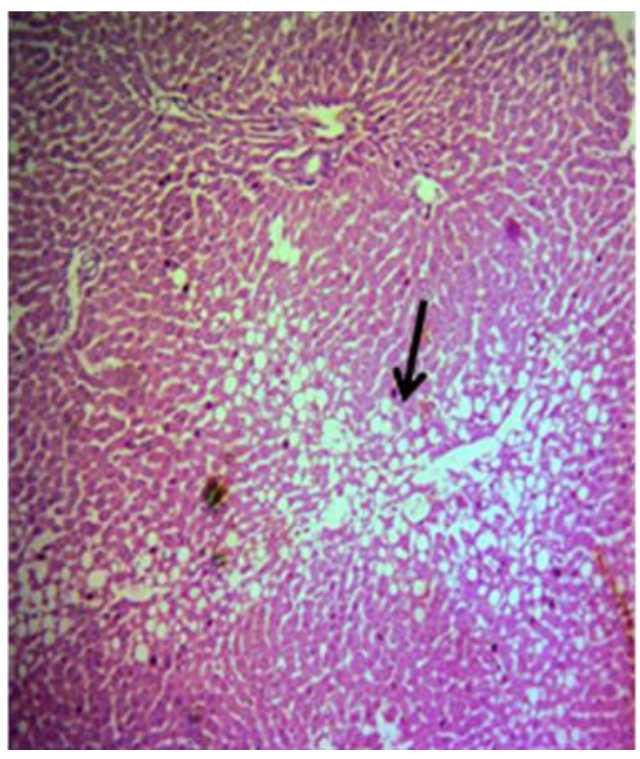

Figure 4. Section of liver: Palm oil treated rats group. Arrow shows severe fatty changes. (H \& E staining, $10 \mathrm{X})$. 
Biochemical and pathological effects in rats

\section{ACKNOWLEDGEMENTS}

The authors highly acknowledged the Bangladesh Agricultural University Research System (BAURES), Mymensingh, Bangladesh for providing the fund to carry out the research.

\section{REFERENCES}

1. Austin MA, McKnight B, Edwards KL, Bradley CM, McNeely MJ, Psaty BM, Brunzell JD and Motalsky AG (2000). Cardiovascular disease mortality in familial forms of hypertriglyceridemia: A 20-year prospective study. Department of Epidemiology, School of Public Health and Community Medicine, University of Washington, Seattle 98195-7236, USA. Circulation.101, 2777-2782.

2. Barek MA (2002). Hemato-biochemical parameters and performances of broiler fed with soybean oil and protein supplementation. Unpublished MS thesis, Department of Physiology, Bangladesh Agricultural University, Mymensingh.

3. Baron BR and Browner WS (1998). Lipid abnormalities, In: Current Medical Diagnosis and treatment. $37^{\text {th }}$ edn., Prentice Hall, New Jersy, 1138-1149.

4. Choi YS, Ahn C, Rhee HI, Choe M, Kim CH, Kim JD, Lee SY and Sugano M (1993). Comparative effect of dietary palm oil, perilla oil, and soybean oil on lipid profiles in differently aged rats fed on hypercholesterolemic diets. Bioscience, Biotechnology and Biochemistry 57: 65-8.

5. Fernandez S, Gonzalez C, Diaz F, Fueyo AM, Gutierrez JM and Patterson AM (1996). Long term effects in two generations of enriched soybean and olive oil diets on some cardiovascular and biochemical parameters in male rats. International Journal for Vitamin and Nutrition Research 66: 393-399.

6. Friedewald WT, Levy RI and Fredrickson DS (1972). Estimation of the concentration of low-density lipoprotein cholesterol in plasma without use of the preparative ultracentrifuge. Clinical chemistry 18: 499-502.

7. Erukainure OL, Ajiboye JA, Lawal BA, Obode OC, Okoro EE, Amisu-Tugbobo AO and Zaruwa MZ (2016). Alterations in atherogenic indices and hypolipidemic effect of soybean oil in normocholesteremic rats. Comparative Clinical Pathology 25: 75-78.

8. Gaiva MH, Couto RC, Oyama LM, Couto GE, Silveira VL, Ribeiro EB and Nascimento CM (2003). Diets rich in polyunsaturated fatty acids: effect on hepatic metabolism in rats. Nutrition 19: 144-149.

9. Go RE, Hwang KA, Kim YS, Kim SH, Nam KH and Choi KC (2015). Effects of palm and sunflower oils on serum cholesterol and fatty liver in rats. Journal of Medicinal Food 18: 363-369.

10. Gomez KA and Gomez AA (1984). Statistical procedures for agricultural research. Second edition. John Wiley and Sons, New York, pp. 207-215.

11. Islam K, Ahemd N, Majumder S, Islam R and Barek MA (2002). Effect of dietary supplementation of soybean oil body weight certain haemato-biochemical parameters in broiler birds. Bangladesh Veterinary Journal 36: 15-17.

12. Islam AKMM and Majumder AAS (2012). Hypertension in Bangladesh: A review. Indian Heart Journal 64: 319 323.

13. Islam MK, Chowdhury MMR, Islam MM, Hoque MN and Rahman MM (2009). Effects of feeding palm oil and soybean oil on body weight and blood cholesterol in black Bengal goats. Bangladesh Journal of Veterinary Medicine 7: 354-357.

14. Jakobsen MU, O'Reilly EJ, Heitmann BL, Pereira MA, Bälter K, Fraser GE, Goldbourt U, Hallmans G, Knekt P, Liu S and Pietinen P (2009). Major types of dietary fat and risk of coronary heart disease: a pooled analysis of 11 cohort studies. The American Journal of Clinical Nutrition 89: 425-432.

15. Jaarin K, Nor-Aini U, Siti-Aishah MA and Das S (2015). Palm oil fat diet consumption and its effects on serum liver enzymes and microscopic changes in experimental Rats. Pakistan Journal of Nutrition 14: 575-580.

16. Kagawa K, Matsutaka H, Fukuhama C, Fujino H and Okuda H (1998). Suppressive effect of globin digest on postprandial hyperlipidemia in male volunteers. The Journal of Nutrition 128: 56-60.

17. Lichtenstein AH (1998). Trans fatty acids and blood lipid levels, Lp (A), parameters of cholesterol metabolism and hemostatic factors. Journal of Nutritional Biochemistry 9: 244-248.

18. Luna LG (1968). Manual of Histopathologic Staining Methods of the Armed Forces Institute of Pathology. $3^{\text {rd }}$ edn., McGrew-Hill Book Company, London.

19. Rahman MA (2009). Effects of some selected fatty acids supplement on haemato-biochemical parameters in rats. Unpublished MS thesis, Department of Physiology, Bangladesh Agricultural University. Mymensingh. Bangladesh.

20. Rahman MA, Jahan M, Karmaker S and Islam MK (2012). Effects of different fatty acid supplementation on body weight and haematobiochemical parameters in rat. International Journal of Natural Sciences 2: 21-25. 
21. Rashid MH, Naser MA, Reza MM, Chowdhury BL and Gheyasuddin S (1998). Changes in the characteristics of fats and oils on cooking and their effects on growth performance of rats. Bangladesh Veterinary Journal 32: 96103.

22. Saha SK, Ahmad N, Majumder S, Hosain MZ and Miah MA (2005). Effects of different edible oils on growth performance, different organ weight and serum transaminases in rats. Bangladesh Journal of Veterinary Medicine 3: 79-81.

23. Sayeed MA, Banu A and Malek MA (2010). Blood pressure and coronary heart disease in noninsulin dependent diabetes mellitus subjects at diagnosis: prevalence and risks in a Bangladeshi population. Diabetes Research and Clinical Practice 39: 147-155.

24. Soler PE and Casado Ruiz V (2010). Epidemiology and risk factors of cerebral ischemia and ischemic heart diseases: similarities and differences. Current Cardiology Reviews 6: 138-49.

25. Steel RG and Torrie JH (1980). Principle and procedures of statistic: A biometrical approach.

26. Wood PDS, Shioda R and Kinsell K (1966). Dietary regulation of cholesterol metabolism. Lancet. 17: 604-607.

27. Xenoulis PG and Steiner JM (2010). Lipid metabolism and hyperlipidemia in dogs. The Veterinary Journal 183: $12-21$.

28. Zaman M, Ahemd J, Choudhury SR, Numan SM, Parvin K and Islam MS (2007). Prevalence of ischemic heart disease in a rural population of Bangladesh. Indian Heart Journal 59: 239-241. 